\section{Serhii Polishko}

\title{
COMPLEX EFFECT OF SULFUR AND PHOSPHORUS ON THE CHARACTERISTICS OF WHEEL STEEL OF KP-T BRAND BEFORE AND AFTER MODIFICATION
}

The object of the research is KP-2 wheel steel modified by the Al-Mg-Si-Fe-C-Ca-Ti-Ce system. One of the most problematic places in the smelting of modern steel is the stability of the chemical composition due to the use of uncontrolled content of scrap, charge and standard modifiers, which are made by the fused method.

To eliminate this problem, multifunctional modifiers were used during the study. This is due to the fact that the KP-2 steel modification method proposed in this article, has a number of features. In this case, the influence modifiers of multifunctional action on the installation of vacuum processing of steel on desulfurization of wheel steel KP-2, obtained under the conditions of the open joint-stock company Interpipe NTRP (Dnipro, Ukraine), was established. In particular, when treating a steel melt with multifunctional modifiers, not only a refining effect occurs, but also an increase in the stability of the chemical composition and level of mechanical characteristics of the KP-2 wheel steel. This is confirmed by the coefficients of variation and interfusion difference presented in the article (span), obtained by statistical processing of a large data set - 442 serial smeltings and 1 modified (6 wheels).

Thanks to the multifunctional modification, the level of mechanical characteristics and the quality of the finished wheels really increases. Compared with similar mass-produced materials, such as FeSi, FeCa, FeMn, SiCa, the use of new multifunctional modifiers in KP-2 wheel steel provides a significant reduction in the mass fraction of sulfur than in the same metal that is processed in the traditional way. It has been established that the use of multifunctional modifiers changes the shape of non-metallic inclusions to globular and reduces their number, which also increases the level of mechanical properties of KP-2 wheel steel. The obtained coefficients of variation prove that the mechanical characteristics of KP-2 modified steel are more stable than in serial melts of the same steel. This will increase the demand and quality of these railway wheels.

Keywords: modifiers of multifunctional action, chemical composition of steel, mechanical characteristics of steel, non-metallic inclusions.

Polishko, S. (2021). Complex effect of sulfur and phosphorus on the characteristics of wheel steel of KP-T brand before and after modification. Technology Audit and Production Reserves, 2 (1 (58)), 11-14. doi: http://doi.org/10.15587/2706-5448.2021.229163

\section{Introduction}

Wheel steel of KP-T brand according to GOST (DSTU) 10791-2016 is a multicomponent system that consists of a large number of chemical elements. Some of them are sulfur and phosphorus, which in significant quantities are extremely undesirable components that significantly reduce the mechanical characteristics and the quality of the finished metal as a whole. In order to reduce their content in this work, let's use modifiers of the Al-Mg-Si-Fe-C-CaTi-Ce system in the conditions of the open joint-stock company (OJSC) Interpipe NTRP (Dnipro, Ukraine) [1]. They help improve mechanical performance by reducing the concentration of unwanted sulfur and phosphorus components. An excess of their content negatively affects the dispersion of the structure, as well as the morphology of nonmetallic inclusions [2]. All this in combination destabilizes the mechanical characteristics of the finished wheels, which reduces their durability indicators, as well as the service life. It is not possible to solve this problem by using such ligatures as FeSi, FeMn, SiMn, FeV, $\mathrm{FeMo}, \mathrm{SiCa}, \mathrm{Al}, \mathrm{CaO}, \mathrm{CaF}_{2}$. Multifunctional modification makes it possible to level this problem, which confirms the relevance of this research.

\section{The object of research and its technological audit}

The object of research is $\mathrm{KP}-2$ wheel steel modified with the Al-Mg-Si-Fe-C-Ca-Ti-Ce system. Analysis of the chemical composition of KP-T serial steel by statistical processing methods showed the following:

- low degree of reduction of sulfur and phosphorus content in KP-T steel;

- unstable chemical composition and mechanical characteristics of KP-T steel treated with serial alloys. 
When using multifunctional modifiers, an increase in the stability of the chemical composition has been proven by methods of statistical processing. The coefficients of variation and the range (the difference between the maximum and minimum value) have been determined. With their help, it was found that the composition of the modified metal is more stable than the serial one. Also, mechanical properties such as tensile strength and toughness are more stable after modification. The use of statistical processing methods is technically convenient, since all the necessary capabilities are available in the standard Microsoft Office software.

\section{The aim and objectives of research}

The aim of this research is to determine the effect of modification with multifunctional modifiers on reducing the sulfur and phosphorus content of KP-T steel.

In order to achieve this aim, the following objectives were set:

1. To determine the indicators of stability of the chemical composition in serial and modified KP-T steel

2. To establish the degree of reduction of sulfur and phosphorus in serial and modified KP-T steel.

3. To establish the effect of modification on the stability of mechanical characteristics.

\section{Research of existing solutions to the problem}

Modern reality puts forward all new requirements for improving the quality of modern materials. In order for rail transportation to be safe, there is a need to improve the quality of railway wheels [3, 4]. However, these works did not consider such problems as a decrease in the content of sulfur and phosphorus with a simultaneous stabilization of the chemical composition and mechanical characteristics.

In [5], the problem of desulfurization is indicated, but nothing is described about a decrease in the phosphorus content. Not a word is also described about the influence of $S$ and $P$ on the level of mechanical characteristics.

An alternative solution to the problem described in [6] does not provide for desulfurization of steel. This is also important when studying the crystallographic texture of rail wheel steel as a result of modification and thermomechanical treatment.

Work [7] is devoted to the study of the effect of a modifier that contains rare earth elements (RE) on the properties of an alloy with a low melting point (Al-Bi-Sb) and a Ca-Si alloy on a high-carbon steel containing 1.9 wt. \% C. But in this work, the issue of reducing the sulfur concentration and the number of nonmetallic inclusions in steel remains unresolved.

Processing with modifiers is described in detail in [8]. However, this publication does not disclose issues that are associated with the stabilization of the chemical composition and the reduction of $\mathrm{S}$ and $\mathrm{P}$ after modification.

Papers [9, 10] provide a brief overview of the latest achievements in the field of improving the properties and performance of engineering materials and structures by using means of out-of-furnace material processing. The research discusses the characteristics of the resulting materials. But at the same time, there is no evidence for desulfurization and dephosphorization of materials.
The authors of [7, 11] have shown that the quality of KP-T wheel steel largely depends on the processing of the melt in the liquid state with multifunctional modifiers. Wheel steel in modern production conditions is a multi-component system. But to date, many problems of the transport metal have not been resolved, such as reducing the content of harmful impurities and obtaining a highly dispersed structure. For this, various modes of thermomechanical treatment are used, as well as the use of various ligatures in a liquid state, such as FeSi, FeMn, SiMn, FeV, FeMo, SiCa, Al, CaO, $\mathrm{CaF}_{2}$, etc. But despite such measures, the problem of stabilizing the chemical composition and improving the quality of finished wheels remains important [12]. This leads to a decrease in the fineness of the structure, coarsening of the morphology of non-metallic inclusions, destabilization of the mechanical characteristics and an unpredictable decrease in the performance of wheel steels. Consequently, the results of the analysis allow to conclude that the most progressive way to improve the quality of carbon steels is to treat them in a liquid state with multifunctional modifiers in the form of briquettes of the Al-Mg-Si-Fe-C-Ca-Ti-Ce system (Fig. 1).

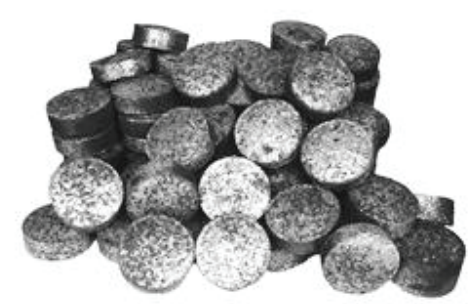

Fig. 1. Appearance of the multifunctional modifier

The above statement, as proved in [1, 13], is justified by the fact that the modifiers in the form of briquettes are completely assimilated by the steel melt. As a result, non-metallic inclusions of a globular shape are formed, which leads to the formation of additional crystallization centers. This, in turn, contributes to an increase in the stability of the properties and quality of the finished metal.

\section{Methods of research}

Microsoft Office features such as STDEV were used to determine stability scores. The difference between the maximum and minimum values of sulfur and phosphorus was also determined, which will determine the level of stabilization of the chemical composition after modification.

Analysis of the chemical composition of KP-T serial steel by methods of mathematical modeling showed:

- insufficient level of refining of KP-T steel;

- unstable chemical composition of KP-T steel treated

in a traditional way with serial deoxidizers.

To obtain accurate and reliable results, a complex of modern methods for determining the properties of the materials under study was used. The chemical composition of steel without modification and after modification was determined using highprecision instruments: Polivak E-600 and LECO (England). Microstructure studies were performed on a NEOPHOT 32 microscope (Germany) at magnifications up to 900 times. Mechanical properties were determined on standard tensile specimens on a MUP-20 tensile testing machine and an MK-30 pendulum tester (Russia). The experimental data were processed using modern computer programs Microsoft Excel 2019. 
Smelting of KP-T wheel steel was carried out in an open-hearth furnace with further processing in a ladle furnace. Heat treatment of wheels was carried out according to the existing production technology in the conditions of OJSC «Interpipe NTRP» (Ukraine).

\section{Research results}

The chemical composition of KP-T steel corresponded to the requirements of DSTU GOST 10791-2016 according to the data of statistical studies of 550 serial and 7 modified smeltings produced by OJSC «Interpipe NTRP» [14].

In the conditions of OJSC «Interpipe NTRP», pilot melting was carried out using multifunctional modifiers. Wheel steels of KP-T brands were smelted on a 100-ton ladle furnace unit. After that, an array of data was collected and systematized on the chemical composition and mechanical characteristics of these brands of wheel steels of open-hearth and electric arc furnace modes to determine the degree of instability of each of the characteristics of the transported metal. For this, the range and variation coefficients of the chemical composition of steels were determined (Fig. 2, 3). As it is known, the lower the coefficient of variation, the more stable the system.

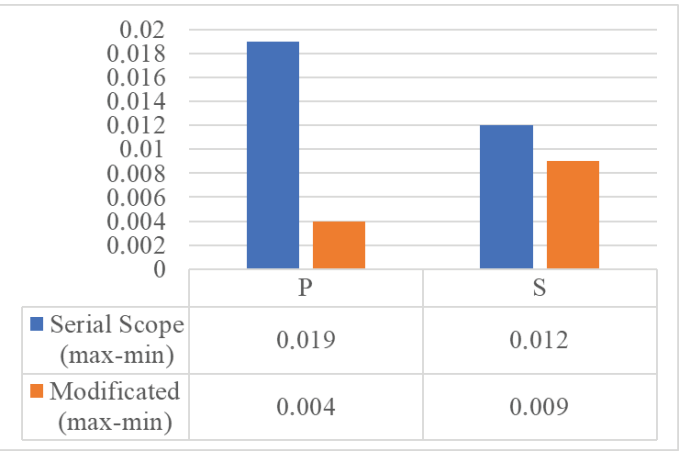

Fig. 2. The difference between the maximum and minimum value of KP-T steel in serial and modified smeltings

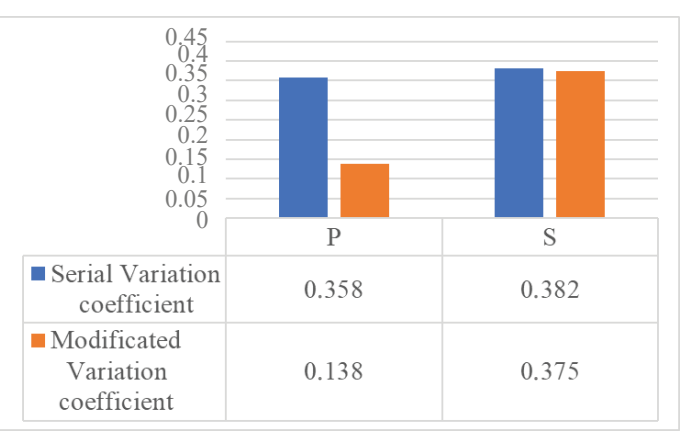

Fig. 3. Coefficient of variation of steel KP-T in serial and modified smelting

The modification resulted in an improvement in the morphology of the non-metallic inclusions. Their structure and morphology of nonmetallic inclusions were investigated on a JEOL JSN-6360LA scanning electron microscope (Japan) equipped with a JED-2300 system. These results are shown in Fig. 4.

The above data confirm that, in modified steel, nonmetallic inclusions, even at high magnifications, have a globular shape and are not stress concentrators.

Under the influence of the modification, the mechanical properties of the modified KP-T steel also increased, which can be seen from Fig. 5 .

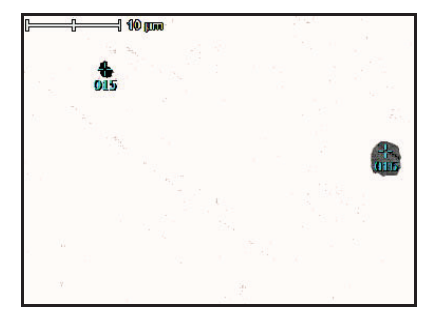

a

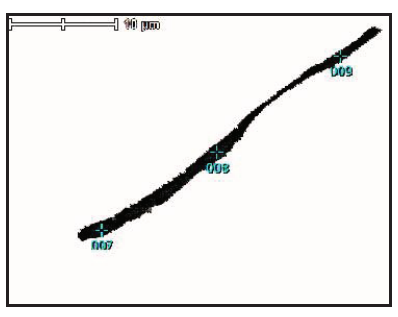

$b$
Fig. 4. Non-metallic inclusions in steel KP-T, $\times 3000$
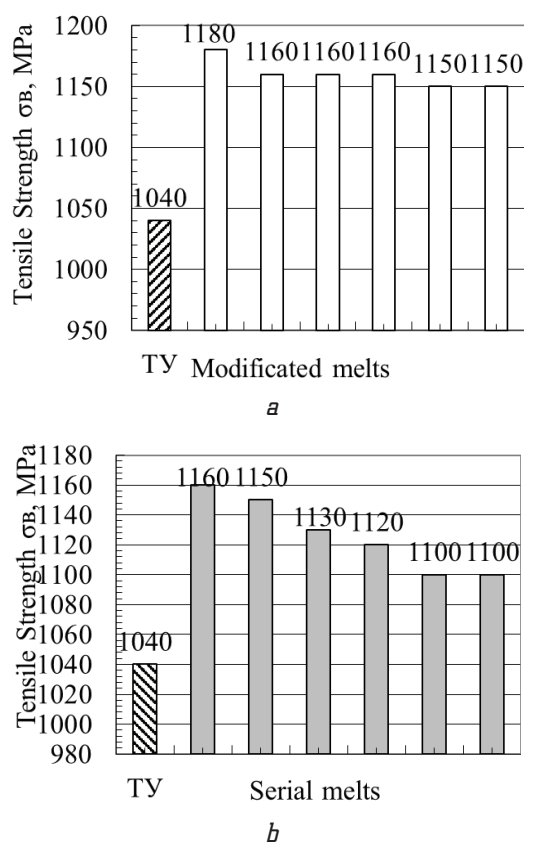

Fig. 5. Histogram of average mechanical properties of wheel steel of KP-T brands: $a$ - serial; $b$ - modified

It was revealed that the obtained properties of the modified KP-T steel are higher than those of the serial steel of the same brand:

- by strength $\sigma_{B}$ by 1.02 times;

- impact strength KCU by 1.14 times;

- by relative elongation $\delta 1.02$ times;

- by the relative narrowing $\psi$ by a factor of 1.06 ;

- by hardness 1006 times.

The results below prove that rework is the most effective way to eliminate such significant drawbacks as the instability of the chemical composition, reducing the content of harmful impurities such as phosphorus and sulfur, which will undoubtedly lead to an increase in the quality of finished wheels.

\section{SWOT analysis of research results}

Strengths. Modification with multifunctional modifiers has a positive effect on the formation of non-metallic inclusions. This leads to a higher level of mechanical characteristics and an improvement in the quality of finished wheels made of KP-T steel.

The positive aspects of the study also include the fact that: - time costs are reduced due to the fact that multifunctional modifiers are produced by a melt-free method within several tens of minutes per piece. While serial deoxidizers are made by the melted method, which takes up to 1.5 hours per piece on average; 
- the efficiency and productivity of steel products in general increases;

- the rate of production of finished wheels increases without loss of quality;

- the production of multifunctional modifiers is environmentally friendly due to their complete assimilation by the steel melt.

Weaknesses. A slight increase in the cost of production for 1 briquette of the modifier, which is leveled by the need for a smaller amount of them when smelting steel in comparison with serial counterparts, which need more, and they are also more expensive.

Opportunities. The use of multifunctional modification in the production of KP-T steel helps to reduce energy consumption and increase the level of mechanical characteristics, while reducing the cost of manufacturing finished wheels. The estimated economic effect of the introduction of multifunctional modifiers is about 40 euros per melt.

Threats. The need to purchase materials (shavings) for the manufacture of briquettes, however, this is offset by the fact that multifunctional modifiers are environmentally friendly and do not need places for burial of industrial waste.

There are analogs similar to these modifiers, but they are made by the fused method with significant energy consumption [15].

\section{Conclusions}

1. The results obtained prove that modification is the most effective way to eliminate such a significant drawback as the instability of the chemical composition. Reducing the content of harmful impurities such as phosphorus and sulfur, undoubtedly, leads to an improvement in the quality of the finished wheels.

2. It has been established that the action of polyfunctional modifiers provides a decrease in the content of nonmetallic inclusions by $30 \%$, stabilization of both the chemical composition and the level of mechanical characteristics of KP-T wheel steel by $20 \%$.

3. Stable chemical composition and mechanical properties play an important role in the use of finished wheels. Modification without significant additional costs ensures the stabilization of the chemical composition and characteristics of steel and is possible due to the implementation of the mechanism of bulk crystallization of the melt, reduction of liquation, and grinding of structural elements.

\section{References}

1. Shapovalova, O. M., Shapovalov, V. P., Shapovalov, O. V., Polishko, S. O. (2011). Pat. No. 93684 UA. Deoxidizing-conditioning agent for processing of smeltings of steels and alloys. MPK:
C22C 35/00, C22C 1/06 (2006.01), C22B 9/10 (2006.01), C21C 1/00, C21C $7 / 06$ (2006.01). No. a200801124; declareted: 30.01.2008; published: 10.03.2011, Bul. No. 5, 4.

2. Murakami, Y. (2019). Metal Fatigue: Effects of Small Defects and Nonmetallic Inclusions. Academic Press, 733. doi: http:// doi.org/10.1016/c2016-0-05272-5

3. Ren, Y., Zhang, L., Yang, W.. Duan, H. (2014). Formation and Thermodynamics of Mg-Al-Ti-O Complex Inclusions in Mg-Al-Ti-Deoxidized Steel. Metallurgical and Materials Transactions B, 45 (6), 2057-2071. doi: http://doi.org/10.1007/s11663-014-0121-0

4. Ostash, O. P., Andreiko, I. M., Kulyk, V. V., Prokopets, V. I (2012). Tsyklichna trishchynostiikist stalei zaliznychnykh kolis typu KP-2 i KP-T za vplyvu ekspluatatsinykh temperaturnosylovykh faktoriv. Problemi mekhanyky zheleznodorozhnoho transporta: Bezopasnost doyzhenyia, dynamyka, prochnost podvyzhnoho sostava, enerhosberezhenye. Donetsk: DNUZhT, 105-106.

5. Sokolov, I. L., Sokolova, E. V. (2020). Osobennosti desulfuratsii nizkouglerodistykh, nizkokremnistoi stali na agregate «kovshpech». Teoriia i tekhnologiia metallurgicheskogo proizvodstva, 3 (34), 4-8.

6. Lychagina, T., Nikolayev, D., Sanin, A., Tatarko, J., Ullemeyer, K. (2015). Investigation of rail wheel steel crystallographic texture changes due to modification and thermomechanical treatment. IOP Conference Series: Materials Science and Engineering, 82, 012107. doi: http://doi.org/10.1088/1757-899x/82/1/012107

7. Liu, K. P., Dun, X. L., Lai, J. P., Liu, H. S. (2011). Effects of modification on microstructure and properties of ultrahigh carbon (1.9 wt. \% C) steel. Materials Science and Engineering: A, 528 (28), 8263-8268. doi: http://doi.org/10.1016/j.msea.2011.07.038

8. Prigunova, A. G., Petrov, S. S. (2016). Structure of metallic melts and its relation with the solid state. Metaloznarstro to obrobka metaliv, 2, 17-27.

9. Brebbia, C., Connor, J. J., Newkirk, J. W., Popov, A. A., Zhilin, A. S (2018). Progress in Materials Science and Engineering. Springer, 203. doi: http://doi.org/10.1007/978-3-319-75340-9

10. Khrapov, G. A., Shilovekikh, O. Iu., Tiulenev, E. N., Dolgikh, Iu. N (2016). Povyshenie effektivnosti desulfuratsii na ustanovkakh kovsh-pech pri obrabotke stali s nizkim soderzhaniem kremniia. Stal, 3, 12-13.

11. Öchsner, A., Altenbach, H. (Eds.) (2018). Improved Performance of Materials: Design and Experimental Approaches. Springer International Publishing AG, 277. doi: http://doi.org/10.1007/ 978-3-319-59590-0

12. Francis, R. A. (2017). An introduction to the metallurgy of steel and its alloys. Ashburton, 182.

13. Polishko, S. O. (2019). Influence of multifunctional modification on stabilization of chemical composition of wheel steels. Journal of Chemistry and Technologies. Bulletin of Dnipropetrozsk university. Series Chemistry, 27 (1), 31-39. doi: http:// doi.org/10.15421/081903

14. DSTU GOST 10791-2016. Kolesa tselnokatanye (2016). Standartinfo, 29.

15. Voinov, A. R., Ri, E. X. (2018). Tekhnologiia kompleksnoi obrabotki stalei na agregate «koush-pech» (ladle-furnace). Khabarovsk: Tikhookeanskii gosudarstvennii universitet (TOGU), 64.

Serhii Polishko, PhD, Senior Researcher, Associate Professor, Department of Production Technology, Oles Honchar Dnipro National University, Dnipro, Ukraine, e-mail: polishkopsa@gmail.com, ORCID: https://orcid.org/0000-0003-4388-2317 